\title{
LA CANDIDEZ DEL CIUDADANO. ANÁLISIS DE LA COMPLICIDAD DE LOS ACTORES POLÍTICOS Y SUS POSIBILIDADES*
}

\author{
Érika Molina García** \\ Universidad de Chile, Chile \\ osiara@ug.uchile.cl
}

\begin{abstract}
RESUMEN: En el entendido de que Ciudadanía y Comunidad son nociones que exigen mantener su significación abierta, no pudiendo abstraerse unívocamente de una práctica político-civil que hiciera las veces de Derecho natural, desarrollamos una interpretación en la cual se interdeterminan plenamente, funcionando en toda Ciudadanía, en cuanto conjunto de acciones y expectativas referidas al espacio público, múltiples ideas de Comunidad: el posicionamiento de cada cual respecto a sus imágenes de Comunidad particulares, fundará su comportamiento ciudadano. En este sentido, examinamos algunos mitos dicotómicos (orden/caos, salud/enfermedad, realidad/utopía, pureza/impureza, etc.) en virtud de los cuales la vida político-cotidiana aparece como una apasionante y embrutecedora novela, incluso para sus heroicos disidentes; examen que acaba revelando una serie de dispositivos de domesticación operativa en todos los actores políticos, incluidos el ciudadano, el sistema económico y el Estado. Finalmente, en la medida en que para los autores tratados a lo largo de este ensayo, el estado político de cosas (las relaciones que usual y regularmente se establecen entre los diversos actores políticos) no se inscribe en una necesidad histórico-destinal, se configura en todo el entramado social una complicidad mutua, que nos responsabiliza y señala a su vez nuevas posibilidades de acción política.
\end{abstract}

Palabras clave: Ciudadanía, comunidad, inmunidad, utopia.

Trabajo recibido el 27 de septiembre y aprobado el 1 de noviembre de 2011.

** Licenciada en Filosofía. Magíster ( $)$ en Filosofía, Universidad de Chile. 


\title{
THE CANDOR OF THE CITIZEN. ANALYSIS OF THE COMPLICITY OF THE POLITICAL ACTORS AND THEIR POSSIBILITIES
}

\begin{abstract}
Assuming that Citizenship and Community are notions that demand an opening of meaning, not being able to be abstracted of a political-civilian practice, acting like a natural Law, we develop an interpretation in which they relate completely, working in any Citizenship, as set of actions and expectations referred to the public space, multiple ideas of Community: our positions with regard to our particular images of Community, will found our civil behavior. In this respect, we examine some dichotomic myths (order/chaos, health/disease, reality/Utopia, purity/impurity, etc.) by which the daily political life appears as an exciting and stultifying novel, even for his heroic dissidents; examination that ends up by revealing a series of domestication devices operative in all the political actors, included the citizen, the economic system and the State. Finally, in the measure in which for the authors treated along this text the political condition of things (the relations that usual and regularly are established between the political actors) is not part of a historical-destinal need, there is formed in the whole social network a mutual complicity, which makes us responsible and indicates new possibilities of political action.
\end{abstract}

Keywords: Citizenship, community, immunity, utopia.

"Dicho de otro modo, en el inmanentismo es la misma comunidad, el pueblo o la nación, lo que es obra, según la asunción romántica de la obra como sujeto y del sujeto como obra."

Existen puntos especialmente sensibles en el discurso de cada cual; confluencias que desembocan en acciones urgentes, aunque muchas veces invisibles, que se presentan como manifestaciones cuya interpretación no puede ser sino oscura, cuyo tratamiento es el más temido, ya que es donde la crítica, ajena o propia, puede reportarnos las mayores frustraciones, a la vez que el más estimado, pues permite ver cómo se han desarrollado honestamente las propias esperanzas o propósitos. Estos nudos críticos tienen siempre un fulgor político, referido a lo público, a nuestra concepción de las relaciones interpersonales o a la vida en común. De modo que aún para el más aislado y solitario de los filósofos, la siempre presente dedicación colateral a los asuntos políticos reportará la más variada gama de beneficios y perjuicios psíquicos. Ya es posible observar con relativa claridad, gracias a una perspectiva expresada muy justamente por toda una generación de filó-

LaCoue-labarthe, Phillippe. La ficción de lo político. Madrid, España: Arena Libros, 2002, p. 91. 
sofos continentales de postguerra, cómo la metafísica en general consiste en determinado discurso autobiográfico, donde los diversos biógrafos de la humanidad, en cuanto protagonistas, ocupan un sitial generalmente heroico de pureza, capacidad intelectual o sacrificial.

La filosofía contemporánea en general continúa un proceso de anti-dogmatismo sostenido por siglos, exhibiendo una especial alerta tras las monstruosidades del siglo XX, la cual no se traduce ya sólo en una desconfianza crítica ante el pasado y una búsqueda de evidencias personalmente confiables -sean intuitivas o racionales-, sino que en la necesidad de responder por dicho pasado. De este modo, ya no basta con haberse percatado, aunque fuese paulatina y fragmentariamente, de los vicios que funcionaban y funcionan al interior de cierta metafísica (la 'de la presencia') sino que es preciso comprender nuestra perpetúa inscripción en la misma, a fin de elaborar nuestras alternativas en una constante prevención. Con la crudeza y lo súbito de los acontecimientos totalitarios se refuerza y masifica una auto-suspicacia que antes acaecía sólo en versiones aisladas. Más allá del rechazo a las formas pretéritas de dominación, habrá que conjurar en nosotros mismos la reacción fácil; la violencia; la ceguera ante nuestra complicidad en los procesos; el rechazo absoluto que impidiese incluso el estudio atento y la comprensión de lo que queremos superar; la simple inversión que nos posicionaría a nosotros en la cima; y la idea misma de superación, con la cual no se hace más que una nueva imposición; y esto no sólo provisoria o metodológicamente, sino que de manera definitiva. Si ha de existir una posición decidida, es la de que no deberán construirse nuevas instituciones imperecederas, o en lenguaje derridiano: si es que existe algo así como la responsabilidad, es preciso que se dé sobre el fondo de la constante indecibilidad.

En esta línea y con el propósito de mostrar cómo la indecibilidad derridiana en materia política no acaba por ser ningún tipo de ambigüedad o quietismo, examinaremos una de las versiones más recientes de la dinámica Comunidad/Ciudadano, extremadamente distinta a todos aquellos modelos en los cuales la Comunidad acaba por absorber las posibles ciudadanías, entendidas como conjuntos de acciones y expectativas referidas al espacio público. Quien actúa profundamente determinado por leyes y proyectos impuestos de manera automática, no ejerce una ciudadanía libre; se trata de un Ciudadano con apellido: un Ciudadano soldado, un Ciudadano obrero, un Ciudadano criatura, un Ciudadano consumidor, un Ciudadano cliente, etc.; un Ciudadano en definitiva inconsciente de las dinámicas en las que participa y que alimenta, y poseedor por ello de una inocencia muy discutible.

En virtud de la intención más o menos generalizada de prevenir la repetición de las monstruosidades del siglo XX, no sólo cabe defender una especie de neutralidad de las nociones de uso cotidiano o disciplinario, tales como Ciudadano o Comunidad, que pueda rellenarse siendo puntualizada de distintas maneras, sino que también es posible elaborar definiciones 
cuyo mérito sea justamente consistir en dicha indeterminación. Tal es el caso de la idea de Comunidad en autores como George Bataille, Maurice Blanchot, Jean-Luc Nancy, Roberto Esposito, Miguel Abensour, etc.

En general la ciudadanía y todas las formas de conducirse en la vida vigilante, habrán de remitir a una responsabilidad sin fuente externa o interna, que llama a la decisión particular e impide "tolerar lo intolerable" 2 en palabras de Nancy, o "aceptar lo inaceptable" 3 en palabras de Abensour, puesto que no existe una autenticidad pura decretada ni un sentido cerrado que valide ninguna clase de segregación o violencia fanática. De modo que la "indeterminación indomesticable" 4 de una Comunidad que habrá de ser caracterizada incesantemente, y, en definitiva, la interpretación que cada uno realiza del vínculo invisible y secreto que nos liga, actuará como una corriente centrífuga que con su caótico circular genera un espacio vacío central relativamente unificado de identidad ciudadana. Así, las versiones de la autobiografía occidental en su fase contemporánea están marcadas por el signo de la multiplicidad y la pluralidad; la ausencia de patrones, de normalización, automatismos y homogeneidad, redundarán en diversas concreciones de una ciudadanía responsable, las cuales se alcanzan sobre todo gracias al análisis de las condiciones paradójicas en las que todo el proyecto anti-dogmático y el afán emancipador moderno reproducen lo que intentan superar: inéditas e imprevisibles formas de subyugación.

El punto crítico de estos análisis está en comprender dónde coinciden y trágicamente se igualan no sólo los totalitarismos de izquierda o de derecha, sino también la democracia en su facticidad, más nociva toda vez que se presenta como el único régimen político posible. Del mismo modo que en una revolución totalitaria, de izquierda o derecha, las verdaderas opciones son degeneradas a una versión dicotómica en la cual, o bien se actúa a favor de la revolución -es decir, se obedece ciega y sordamente a los mandatos fundamentalistas de unos dominadores ahora encubiertos como libertadores-, o bien se está en contra de la misma. Durante la democracia se ofrecen como únicas alternativas el participar activamente del sistema o estar contra la supuesta paz que reporta el mismo. Así, la democracia no sólo queda percibida como la única opción, sino que como la mágica solución, cargada por los valores de bondad y justicia. En general, todas las dicotomías tomadas como algo más que diferenciaciones provisionales o metodológicas, en el contraste desproporcionado que provocan, generan ilusiones de ese tipo, y constituyen la principal herramienta de esa metafísica de la presencia de la cual somos partes, y sin embargo encaramos.

\footnotetext{
NANCY, Jean-Luc. El sentido del mundo -3a edición- Buenos Aires, Argentina: La marca editora, 2003, p. 125.

abensour, Miguel. Para una filosofía politica crítica. Barcelona, España: Anthropos, 2007, p. 137.

Ibid. p. 322.
} 
Así, una enorme fracción de la labor filosófica de los pensadores aquí referidos consistirá en desarticular, desactivar o, si se prefiere, desconstruir toda clase de ficciones, gesto que se traduce como una lucha por diversos frentes ante la simplificación de los fenómenos (sociales, políticos, emocionales, etc.), en todas sus formas.

\section{LA ILUSIÓN MÉDICA}

Como caso paradigmático de las diversas mitologizaciones simplificadoras que, no sin una intencionalidad muy específica de por medio, son utilizadas para reproducir e imponer un régimen político, unos planes de vida, un modelo de sociedad o unos patrones de comportamiento privado, analizaremos brevemente la metáfora médica en algunas de sus infinitas aristas. Lo que podríamos llamar en vocabulario abensouriano la 'medicalización del poder', que en términos generales consiste en convencer al Ciudadano de que se encuentra en cuanto tal enfermo, que la ciudad en que habita está desequilibrada, al borde del caos, y que para evitar un inminente shock séptico debe aceptar sumisamente el sistema político que se le impone como tratamiento, dota a la autoridad de una superioridad e inaccesibilidad totales, donde el "señor es, simultáneamente, legislador, médico, pedagogo" 5 . Aunque Abensour nos está hablando en particular del régimen totalitario maoísta, no es difícil advertir en el cotidiano la presencia de la dicotomía salud/enfermedad, según la cual toda heterogeneidad y anormalidad -en su acepción literal de fuera de la norma, norma siempre impuesta- se percibe como inminencia de lo más rechazado, de lo más espantoso, de la muerte, y su superación como lo más urgente. Esta simplificación, no sólo truculenta en su eliminación estratégica de los puntos medios entre salud y enfermedad, sino que también en su apelación al terror del Ciudadano, funciona gracias a una idealización absolutamente falsa de la salud como un estado de paz absoluta, de ausencia total de incomodidades y de dolor.

Parece mentira que con la experiencia constante de nuestro propio cuerpo, con todas sus fatigas y dolencias, sensaciones placenteras y molestas, en la interdependencia de sus intensidades, podamos creer en la posibilidad y menos en la bondad de un estado de letargo total y de ausencia de la diferencia, como si lo que buscáramos fuese la somnolencia, o peor aún, algo así como un estado de coma. Y sin embargo, todas las ideas de Comunidad que han inspirado los regímenes políticos más atroces y hasta aquellos que ni siquiera merecen el título de régimen político, pues suprimen todo espacio en el cual alguna libertad política pudiese desarrollarse, han consistido en la conformación de unidades fusionales hipersubjetivas, ininterrumpidas y naturalmente necesarias. De hecho, escuchando la lectura abensouriana de Claude Lefort, podemos fijar lo más característico del totalitarismo en la auto-interpretación de un pueblo como cuerpo. La imagen de cuerpo (aunque no del cuerpo y las sensaciones como los experimenta-

Ibid. p. 136. 
mos segundo a segundo, sino que en una interpretación purificada) dictamina la fusión de una Comunidad en una unidad indiferenciada, que correlativa e inmediatamente genera una exterioridad con "el estatus de enemigo maléfico". 6

Aunque para autores como Philippe Lacoue-Labarthe ${ }^{7}$, esta organicidad de la política, que es en definitiva la organicidad de la Comunidad, posiblemente esté presente en toda elaboración identitaria de una nación o pueblo y no tenga que necesariamente interpretarse biológicamente reduciéndola a una raza, en atención a la amplitud de la idea de physis en comparación con la idea de bios, es notable cómo por esta interpretación del totalitarismo se hacen comprensibles, aunque permanezcan como injustificables, los comportamientos de quienes guardaban silencio, o fueron activos en la reproducción de la barbarie, como si su sometimiento fuese su bien más preciado. En efecto, quien se percibe no como fracción vinculada, comunicada justamente en la medida en que es una porción separada del todo, sino que como una manifestación del poder que lo domina, sin percibir esa dominación como tal, sino que identificándose absolutamente con ella en un mismo cuerpo, adquiere la idealidad de las dicotomías (interior/ exterior, pureza/impureza, etc.) como modelo de pensamiento, valorando así por sobre todo el bienestar y la protección del Uno orgánico sobre sí mismo y sobre cualquiera, persiguiendo el exterminio de todo elemento contaminante, ya sea externo o interno. De este modo se generaría una colaboración que no permitiría hablar de una dominación ejercida desde fuera, como por un tirano, sino que actúa desde lo más íntimo de cada cual, desde su auto-interpretación más personal, y la coincidencia absoluta de esta con el todo orgánico. La igualdad queda imposibilitada; se trata de una absoluta identidad.

Para la camada de biógrafos a la que atendemos aquí, la Comunidad en cualquiera de sus formas consiste, siguiendo con la metáfora médica, en un contagio comunicativo de unos ideales auto-interpretativos, de unas pretensiones de ser: pretendemos que somos una clase contra otra clase, una unidad orgánica racial, o incluso que somos dos personas fusionadas en una cuando nos amamos. Todas son performances corales que disfrutamos tal como disfrutamos cualquier juego, a veces con la mayor seriedad y el convencimiento más firme, pero ante cuyas consecuencias deberíamos mantenernos siempre atentos. En este sentido, la expresión de ideales ajenos asumidos como propios, no generados en nuestro juicio resulta especialmente grave; debemos sabernos portadores de una capacidad propagandística enorme, como si fuésemos portadores de un virus, posiblemente letal o vitalmente secreto, en el mejor de los casos: el del secreto sentido de la Comunidad como indeterminación. Sin embargo, en este punto es preciso distinguir entre tres significados de Comunidad: en primer lugar como un hecho dado y permanente, previo a que podamos siquiera proponernos pensarla; en segundo lugar, como una imagen que se elabora a partir de ese hecho dado, pero que necesariamente lo deforma y

Ibid.p. 191.

7 LACOUe-labarthe, Phillippe, op. cit. (n.1), p. 89. 
manipula; y en tercer lugar como una articulación a partir de la imagen que adoptamos del lazo dado, es decir como el ordenamiento legal que nace de la imagen de Comunidad respectiva, la cual puede referir a un pueblo o a varios, a un continente o a varios, etc.

Aunque experimentamos la existencia de la Comunidad en su primer sentido, y no podemos sino al menos enunciar dicho dato, no debemos arrogarnos la capacidad de identificar sus características y límites precisos, sino sólo de elaborar una imagen, respecto a la cual somos ya responsables. Tal como para el filósofo argentino Carlos $\mathrm{Nino}^{8}$, los derechos humanos son un recurso artificial perfectible creado por algunos hombres y mujeres en un momento determinado y reciente de la historia, justamente en la medida en que todo el resto del derecho como código escrito de normas lo es, la Comunidad a la que podemos referirnos no es la Comunidad natural. Esto, tal como indica también Nino respecto a los derechos humanos, no va en detrimento de que mantenga una relación de dependencia respecto a ciertos hechos naturales, ni de su trascendencia social.

Siendo para todos difícil sustraernos a los efectos de la metáfora médica, ésta transita a través de las diversas imágenes de Comunidad facilitando no sólo una domesticación del Ciudadano fundada en el terror -en algo así como un terrorismo metafórico-, sino que también la domesticación de otros actores políticos, puesto que la realización de sus principales mandatos (proteger una esencia determinada de lo externo y superar toda remota contaminación) exhibe sin cesar su contradicción. En esta línea, podemos observar junto a Roberto Esposito ${ }^{9}$, una serie de supuestos tratamientos que no hacen sino agravar o continuar la enfermedad que esperan curar. Inmunizaciones que buscan que la sociedad entendida como Comunidad exonere sus males a partir de sus propios anticuerpos, lo cual implica atribuirse la capacidad de conocer todas las características y los mecanismos de funcionamiento más profundos de dichos anticuerpos, lo que equivale a poseer una definición anudada de lo propio y la dinámica defensiva del cuerpo como la hemos visto.

Desde determinado acuerdo común al cual se adhiere para protegernos de la violencia mutua, pero que sólo puede aplicarse y defenderse con más violencia, hasta un Estado que se presenta como regulador de la economía con sus dinámicas sordas a los Ciudadanos y sin embargo omnipotentes, determinadoras de hasta los aspectos más básicos de la vida, pero que a su vez necesita ser regulado, pues acaba convirtiéndose en un aparato administrativo centralizado sordo a su vez, dependiente de los mecanismos siempre insuficientes -dada la necesaria practicabilidad- de legitimación representativa, todos las variables políticas se encuentran, en definitiva, determinadas por una especie de engaño muy especial: un auto-engaño, que se alimenta de nuestras propias ilusiones identitarias, como si pretendiéramos dejar de tropezar y sin embargo nunca quitásemos las manos de encima de nuestros párpados.

\footnotetext{
Nino, Carlos. Ética y derechos humanos -2a edición- Buenos Aires, Argentina: Astrea, 1989, p. 1.

9 Esposito, Roberto. Comunidad, inmunidad y biopolitica. Barcelona, Espańa: Herder, 2009, p. 19.
} 
Evidentemente, la contradicción no está en la inalienable compulsión auto-definitoria, sino que en creer poder definir una sola esencia para cualquier clase de Comunidad o para cada uno de nosotros. Creencia casi religiosa, en la cual co-actúan toda clase de simplificaciones tradicionales y ficciones como las contenidas en la metáfora médica. Tras advertir la existencia de estas alternativas dicotómicas derechamente falsas, lo que sigue en el camino de nuestros autores no será necesariamente desechar las metáforas ni los significantes tradicionales, sino que desmitificarlos y re-significarlos, enriqueciéndolos cada vez más, como correspondería hacer con un cuerpo que no es una unidad perfecta, sino que tiene órganos más vitales que otros, una gama de movimientos habituales que sin embargo puede expandir manteniendo unos límites que nunca podrá sobrepasar, con unos dolores y unas dificultades fundamentales para su bienestar, una piel que lo contacta con otros cuerpos que están siempre ahí, con él, y sobre todo una inmunidad que "aunque sea necesaria para nuestra vida (...) llevada más allá de un cierto umbral, acaba por negarla, encerrándola en una suerte de jaula en la que no sólo se pierde nuestra libertad, sino también el sentido mismo de nuestra existencia individual y colectiva" ${ }^{\prime 10}$.

\section{UTOPÍA Y MITO}

Con todo lo dicho hasta aquí, tenemos que dedicar un tiempo a meditar sobre una suspicacia de suspicacia: la sospecha de que podemos, sin darnos cuenta, fomentar las simplificaciones con nuestro análisis de la complicidad de los actores políticos en cuanto inmersos en una autobiografía general plagada de imágenes que impiden la autocrítica, solazándonos en nuestros propios vicios psíquicos, como el del soldado que se siente especialmente aliviado cuando pertenece a una masa indiferenciada, o el del heroico anacoreta que se siente análogamente orgulloso al abandonarla. En efecto, con facilidad podríamos deducir de esto aquella clase de psicologismo burgués al que los marxianos están tan atentos, o dicho de otra manera, podríamos reducir todas las dificultades concretas de las personas, sus injustas y espinosas condiciones materiales, a problemas imaginarios, con una psicología barata que, por ejemplo, cifre el malestar de la mayoría de la población en el código de la frustración, la envidia o el resentimiento.

Sin embargo, no debemos condenar la exploración de imágenes, emociones y auto-interpretaciones, confundiéndola con el psicologismo fragmentador, que siempre impide valorizar adecuadamente los fenómenos y que muchas veces es utilizado sin pudor para despreciar los movimientos de izquierda. Aunque personalmente no soy parte de ninguna clase, por lo cual mi acercamiento a la teoría marxista es en general sólo teórico, la comprendo y no me atrevería a reducir las clases sociales a meros estados de ánimo, si con ello vamos a entender una simplificación fisicalista dependiente de la inaceptable dicotomía tradicional mente/cuerpo, y no la vida en su integridad concreta, o, si se prefiere, material. No obstante, habremos de tener mucha precaución con este título, ya que la materialidad es utilizada de maneras muy diversas en

Ibid. p. 17. 
los autores que hemos intentado filiar, siendo todos expositores recientes de un mismo corpus autobiográfico. A partir de aquí, tendremos que acentuar las diferencias, las cuales, en todo caso nos permitirán comprender con mayor claridad el acuerdo autocrítico de toda una generación; y lo haremos concentrándonos, por una parte en Abensour, y por otra en Nancy.

Para Miguel Abensour, uno de los mejores olfatos cuando de reconocer falsas alternativas y dicotomías se trata, la materialidad estará relacionada justamente con la imagen corporal que hemos desarrollado aquí, es decir con aquella simplificación responsable de la crueldad característica de nuestra era. Podríamos decir que para él la definición de una identidad esencial, motor de lo que debemos prevenir y que por ningún pase mágico quedará ausente de nuestras posibilidades venideras, tiene que ver justamente con una materialidad que se presenta como naturaleza necesaria y manifiesta para algunas personas, sean éstos profetas, videntes, caudillos, o iluminados de cualquier tipo. En este sentido las condiciones materiales están cargadas de un tono negativo, pero sólo en la exacta medida en que una intimidad ideal, u otro mundo como el de los religiosos también lo están: en cuanto fijan un sentido que se revela, y justifica así lo injustificable. Habrá que ir a pensar lo político y la Comunidad entonces "más allá del carácter recíproco de las necesidades, del juego de intereses, de la división del trabajo y de sus efectos, como relación, como nexo propiamente humano"11. Opción que se traduce en la idea abensouriana de Utopía, la cual es sujeto de las más características de las alternativas falaces, como aquellas que la oponen al realismo, a la democracia, a la ciencia, o a toda clase de vida activa.

Con Abensour la Utopía deja de significar una quimera irrealizable o cuya única acción consiste en influenciar de manera indirecta las acciones, para pasar a ser un campo acabado de fenómenos. La mitologización, tal como la hemos visto hasta aquí, no será más que un tipo de Utopía, y en todo caso no el más importante, pues resulta mucho más relevante para este autor el rol que ha jugado contra todo tipo de dominación. No es banal que los totalitarismos o en general los regímenes políticos en cuanto organizaciones interesadas en alcanzar y mantener el poder de subyugar a la mayoría, no sólo pretendan ser un cuerpo puro y bien delimitado, sino que busquen debilitar e incluso eliminar toda disidencia, conflicto u oposición (todas figuras utópicas), como si estuviesen de antemano persuadidos de que en realidad no lo son. La compulsiva búsqueda de la unidad o la unidimensionalidad a través del rechazo y la negación, se fundan en una inseguridad y miedo profundos, quizás por la consciencia secreta de la indecibilidad que se viene en las últimas décadas enfatizando. La Utopía sería esa región manifiesta en su ambigua etimología, entre un buen lugar y un no-lugar, pero con seguridad un lugar otro, el lugar de la posibilidad, no en su sentido moderno, o mejor dicho, no sólo en su sentido moderno, en cuanto límites de lo experimentable, sino que en tanto que ausencia, o en cualquier caso indeterminación, de los límites de la experiencia posible.

11 abensour, Miguel, op. cit. (n.3), p. 9. 
Las posibilidades de actuar en el estado político de cosas, el cual, aún cuando nos lo ocultemos, nos mantiene en una tensión psíquica pues en más de alguna ocasión salimos de nuestra candidez y advertimos la complicidad en alguna de sus múltiples formas, siempre serán fraguadas en territorio utópico. Es así cómo en el caso de Abensour, más allá de las tareas que incesantemente se abren en la meditación de lo político, existe una posibilidad democrática, entendiendo la democracia fuera de su tramposa identificación con la centralización burocrática que constituye el Estado. Se trata de una democracia salvaje, en cuanto rehúye la definición y se desarrolla contra y en el desborde de las instituciones tradicionales y "los referentes de certidumbre" 12 . Ésta sería la manera de acoger la heterogeneidad y el conflicto perpetuo que alcanza la autobiografía humana cuando se decide a no cesar en su auto-interrogación y a no fijar simetrías ni unidades ficticias como verdaderas revelaciones.

Por otro lado, con Nancy la materialidad tiene una connotación totalmente distinta, no obstante, como observaremos, las diferencias en la repartición de títulos no se dan porque ambos autores intenten expresar cosas distintas, sino que en cuanto Nancy ya se encuentra ensayando el nuevo estilo auto-biográfico que no busca fijar esencias, ya está re-significando o, mejor dicho, in-significando las locuciones usuales, dejando algo de lado, aunque no completamente, la comparación con los modelos tradicionales. Salir de las dicotomías de hecho/valor, objeto/sentido o real/ideal significa salir, entre otras cosas, del esquema onto-teológico que decreta que la materia o el mundo material no tiene sentido en sí mismo, pero que sin embargo, lo encuentra en otro mundo, en un "lugar sin lugar", o "en el afuera de la totalidad de los lugares"13. Algo así como una utopía cristiana que completa aquella visión en que el mundo es un vacío de sentido que sólo se puede rellenar con ese otro mundo o con el de la interioridad de la criatura que lo replica. Dilapidada esta táctica de sentido, la mera experiencia del tacto de las cosas, de las cosas a secas, de nosotros mismos y los otros en cuanto tales, mostraría que "la idealidad del sentido es indisociable de su materialidad" 14 , y no en la acepción clásica de sustrato.

Toda abstracción de una forma tendiente a una perfección imaginaria (toda idealización) precisa que percibamos alguna cosa en particular, con lo cual la materialidad deja de ser una masa, una inherencia básica indiferenciada, para pasar a ser la diferencia misma en tanto singularidad, y con ello el carácter del sentido y el mundo, entendidos como nombres de la misma exposición total de la existencia. En estas circunstancias el Ciudadano, es decir "una localización múltiple, sobredeterminada y móvil" 15 , será la figura que responde mejor en materia política, confrontándose a la idea de sujeto político, que representará eminentemente el modelo tradicional y apropiador de sentido que se intenta reelaborar. Aunque no sea posible hasta ahora encontrar una política pura del sujeto o una política pura del Ciudadano, Nancy cree ver una

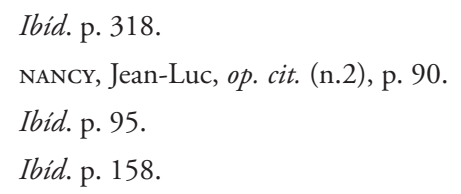


clara diferencia, pues son maneras completamente distintas de vivir la Comunidad y de reivindicar la Soberanía. Sin embargo, no habrá que entender la Ciudadanía sólo como abstracción espacial o vacío, pues sería continuar con la autosuficiencia del sujeto, simplemente anteponiendo el signo de la negación.

El Ciudadano no es quien no se instituye una esencia, sino quien ejerce y asume la multiplicidad de identidades, resistiéndose a la tentación de fijar alguna, porque "el sujeto totalitario se revela suicida, pero la democracia sin identificación se revela también sin demos y sin kratein que le sea propio"16. En este sentido, podemos sentirnos como Ciudadanos poseedores de un nuevo derecho muy particular, el de desarrollar las imágenes que queramos, con los sentidos que nos parezcan más adecuados, en una igualdad por fin efectiva donde "Cada uno desplaza o desarregla la soberanía y la comunidad” 17 . Aún cuando para más de alguno esta especie de manifiesto de la libre interpretación (libre en el sentido de poder abandonarla junto a la significación, en tanto que arrogantes pretensiones de saber una esencia) parezca una propuesta mucho menos que concreta, tanto en Abensour como en Nancy encontramos una intención común: mostrar la ausencia de referencia de la existencia. Nadie puede imponerse apelando a la autoridad de referente alguno; es eso lo que concretamente se sigue como consecuencia. No existe otra realidad que la nuestra, y por lo tanto, no puede continuar entendiéndose la materialidad como carente de algo, ya sea de las ideas, del sentido o de otros tiempos; todo habrá de ser encontrado en la misma experiencia, y el desafío y las tareas políticas surgirán del mantenerse en esa indefinición 'a secas', anticipándonos a los malentendidos por los que solemos intentar controlarla.

\section{CONSIDERACIONES FINALES}

“No estamos en una 'guerra de civilizaciones', estamos en un desgarrón interno de la civilización única que civiliza y barbariza el mundo con un mismo movimiento, porque ella ha tocado ya el extremo de su propia lógica: ella ha remitido el mundo por completo a él mismo, ella ha remitido la comunidad humana por completo a ella misma y a su secreto sin dios y sin valor de venta" 18

La Comunidad que se revela a la sazón de las últimas reflexiones de la sociedad sobre sí misma es efectivamente global, mundial en el sentido en que pone en juego toda una civilización que como un solo individuo se ha auto-interpretado, y por cuyos errores debemos todos responder. La respuesta no es fácil, sino más bien la más difícil de todas, pues implica en pa-

\footnotetext{
Ibid. p. 163.

Ibid. p. 170.

18 BLANCHOt, Maurice. La comunidad inconfesable -2a edición- Madrid, España: Arena Libros. 2002, p. 114. Postfacio de JeanLuc Nancy.
} 
labras de Nancy "atreverse a pensar lo impensable, lo inasignable, lo intratable del ser-con sin someterlo a ninguna hipóstasis." ${ }^{19}$. Sin embargo esta dificultad, agravada por las ineptitudes y aporías funcionales del sistema social, no ha de detener, al menos la proliferación de voces.

Para terminar, hemos de hacernos cargo aún de otra suspicacia de suspicacia, ya que, aún cuando estos autores lleven las ideas de tolerancia y revolución a nuevos y lúcidos niveles, y aún cuando exhiban las intenciones disfrazadas de ideales que en juventud a todos nos pueden parecer inocentes, como los de una sociedad reconciliada o de una Comunidad de ideales que pueda llevar a todo un segmento de subyugados sociales al poder político, existen a mi juicio aún semillas sospechosas, que intentaremos al menos enunciar preventivamente, aunque resulte completamente imposible prevenir todos los malos usos de los que pueden ser víctimas hasta las teorías más nobles. Podemos pensar fácilmente en el utilitarismo de John Stuart Mill usado para el progreso del complejísimo sistema económico-social en el cual hoy estamos insertos y que, sin embargo se fundaba en una idea de justicia asombrosamente coincidente la idea de indecibilidad aquí esbozada, la cual expresaba esa circunstancia de igualdad profunda, respecto a la cual profiere: "Cada uno desde su propio punto de vista es irrefutable. Cualquier toma de posición con respecto a uno u otro, con fundamento en la justicia, tendrá que ser totalmente arbitraria. Sólo la utilidad social puede decidir la preferencia”. ${ }^{20}$

En el caso de los autores aquí examinados, debemos tener presente que el peligro no está en la aceptación de la multiplicidad postulada, sino que en la auto-interpretación heroica que puede surgir del definirse a defenderla y ejercerla. En efecto, en cuanto el conservadurismo y el afán controlador se basan en el miedo y la inseguridad, es preciso que para remontar la comodidad del yugo tradicional y ejercer una nueva meditación o acción, carezcamos de ese miedo. No obstante, esto no necesariamente tiene que redundar en la auto-apreciación del actor político como un ciudadano valiente, aún cuando exista, por ejemplo, a ojos de Abensour "una concepción sorprendentemente sobria del heroísmo" ${ }^{21}$, donde el héroe es completamente igual a sus conciudadanos, destacándolo únicamente su valor. Sin embargo, en mi opinión quien actúa sin temor sólo se torna valiente o heroico ante los ojos de otros, o de él mismo en tanto otro, y ésta, a mí modo de ver, sería una de las auto-apreciaciones de las cuales más habría que cuidarse, intentando actuar, por así decirlo, en una inconsciencia respecto a la propia acción, no a sus elementos, condiciones y consecuencias, sino que a su calificación estética, por así decirlo.

Y en todo caso, habría que estar atentos ante un vicio posiblemente inherente a toda autobiografía, en el sentido en que toda auto-interpretación depende de la definición en oposición a lo diverso, o bien, vislumbrar y ensayar como invitan a hacerlo los autores examinados aquí, la posibilidad de una auto-interpretación identitaria nutrida de la indeterminación y la

\footnotetext{
Ibid. p. 113.

MILl, John Stuart. El utilitarismo -3a edición- Madrid, España: Alianza, 1991, p. 124.

ABENSOUR, Miguel, op. cit., p. 120.
} 
heterogeneidad. En este sentido, resultarían especialmente relevantes los motivos psíquicos que posibilitan la fragilidad ante las dicotomías abruptas, tales como la tentadora sensación de la pertenencia a una masa indiferenciada, o a una hipersubjetividad en relación a la cual podemos comportando como héroes, sacrificándonos por su bien, o en la antípoda, esforzándonos en disidir sin elaborar el sentido de esa disidencia. Lo crucial sería conservar la crítica en todo momento, la crítica aún sobre las actitudes aparentemente críticas, y la suspicacia ante cualquier estabilidad y sosiego.

\section{REFERENCIAS BIBLIOGRÁFICAS}

abensour, Miguel. Para una filosofía política crítica. Barcelona, España: Anthropos, 2007.

вLANCHOt, Maurice. La comunidad inconfesable -2a edición- Madrid, Espańa: Arena Libros, 2002.

esposito, Roberto. Comunidad, inmunidad y biopolitica. Barcelona, España: Herder, 2009.

Lacoue-Labarthe, Phillippe. La ficción de lo politico. Madrid, España: Arena Libros, 2002.

MILL, John Stuart. El utilitarismo -3a edición- Madrid, España: Alianza, 1991.

NANCY, Jean-Luc. El sentido del mundo -3a edición- Buenos Aires, Argentina: La marca editora, 2003.

NINO, Carlos. Ética y derechos humanos -2a edición- Buenos Aires, Argentina: Astrea, 1989. 